\title{
Langlopend grootschalig onderzoek naar kinderen en jeugdigen in Nederland: Wat heeft het gebracht en waar leidt het ons naartoe?
}

\author{
M. Klein Velderman • F.D. Pannebakker
}

Published online: 27 March 2015

(C) Bohn Stafleu van Loghum 2015

\begin{abstract}
Samenvatting De laatste decennia zijn er in Nederland op het terrein van kinderen en jeugdigen enkele langlopende grootschalige studies uitgevoerd. Dergelijk onderzoek kan waardevolle informatie opleveren voor beleid en praktijk van de zorg voor jeugd. In dit onderzoek stonden interviews centraal met projectleiders van een aantal Nederlandse grootschalige longitudinale of herhaalde transversale studies op het terrein van kinderen en jeugdigen, te weten Generation $R, A B C D$, Universiteit Utrecht PIAMA, TRAILS, KOALA, C4Youth en HBSC. Het doel was inzicht te verkrijgen in de opbrengsten van deze studies tot dusver. In de interviews werd gevraagd naar karakteristieken van de studies, belangrijkste opbrengsten van het onderzoek in termen van beleid, onderzoek, en praktijk, en factoren die de studie positief en negatief beïnvloed hebben. Tot slot werd gereflecteerd op witte vlekken in relatie tot kennis en beleid op het terrein van kinderen en jeugdigen in Nederland waarop een longitudinale studie volgens de projectleiders mogelijk een antwoord zou kunnen geven. Op basis van de interviews concluderen we dat langlopend onderzoek een waardevolle bijdrage levert aan de zorg voor jeugd in Nederland. In de discussie schetsen we daarbij een beeld van de toekomst, inclusief inhoudelijke richtingen voor verder onderzoek.
\end{abstract}

Wij danken de heer dr. Ferko Öry voor het interviewen van de projectleiders van de studies, en de betreffende projectleiders voor hun bereidwilligheid en openheid in dit onderzoek.

M. Klein Velderman $(\bowtie) \cdot$ F.D. Pannebakker

Afdeling Jeugd, TNO,

Leiden, Nederland

E-mail: Mariska.kleinvelderman@tno.nl
Inleiding

Nederland investeert doorlopend tijd en geld in begeleiding van kinderen, jeugdigen en gezinnen in termen van preventie en zorg. Kennisinstellingen doen onderzoek naar de effectiviteit en doelmatigheid van deze investeringen, zo mogelijk via longitudinaal onderzoek op dit terrein. Om iets te kunnen zeggen over ontwikkelpaden van jeugdigen, over de effecten van begeleiding en zorg op langere termijn, en over wat werkt voor wie, zijn langlopend onderzoek en goede, uniforme monitoring nodig. Het prospectief volgen van groepen kinderen die geïdentificeerd zijn in een bepaalde periode stelt de onderzoekers in staat om zonder (geheugen)bias associaties te zoeken tussen kenmerken van het kind, het gezin, leefomgeving en leefstijlfactoren, en latere uitkomsten op het gebied van gezondheid en andere domeinen. Het combineren van (deels) fundamenteel onderzoek, zoals genetisch onderzoek met observationeel en empirisch onderzoek, geeft bovendien inzicht in 'nature and nurture' en in het samenspel tussen beiden. Het prospectief volgen van kinderen en jeugdigen die bepaalde vormen van zorg voor jeugd krijgen stelt onderzoekers in staat om na te gaan welke uitwerking de verschillende zorgvormen op kinderen en jeugdigen hebben, waarin voor elk kind en voor elke jongere in zijn/haar profiel, leefomgeving en leefstijlfactoren zijn verdisconteerd.

De afgelopen decennia is op het terrein van kinderen en jeugdigen een aantal belangrijke grootschalige langlopende longitudinale en herhaalde transversale studies uitgevoerd. Hoe zit het met de opbrengsten van deze studies? Te denken valt aan de vele wetenschappelijke publicaties en promoties die uit deze studies voortvloeien. Maar de opbrengsten reiken verder dan dat. Landen onderzoeksresultaten ook in beleid en praktijk? Hoe is de onderlinge aansluiting tussen de verschillende studies? Welke wetenschappelijke en maatschappelijke vraagstukken zijn beantwoord? Wat zijn de belangrijkste 
lessen voor het blijvend succesvol uitvoeren van langlopende (longitudinale) studies in Nederland? En wat zijn de witte vlekken die resteren ten behoeve van verder wetenschappelijk onderzoek en beleidsinformatie? Dit artikel gaat over Nederlands grootschalig longitudinaal en herhaald transversaal onderzoek op het terrein van kinderen en jeugdigen en heeft als doel inzicht te krijgen in wat het onderzoek tot nu toe heeft gebracht en waar het naartoe leidt in termen van onderzoek, beleid, en praktijk.

\section{Methode}

Projectleiders van Nederlandse grootschalige longitudinale en herhaalde transversale studies op het terrein van kinderen en jeugdigen kregen in februari 2013 namens de directeur van ZonMw een uitnodigingsbrief voor een interview. Het betrof projectleiders van de volgende zeven studies: Generation R, ABCD (the Amsterdam Born Children and their Development study), Universiteit Utrecht PIAMA (Preventie en Incidentie van Astma en Mijt Allergie), TRAILS (TRacking Adolescents' Individual Lives Survey), KOALA (Kind, Ouders en gezondheid: Aandacht voor Leefstijl en Aanleg), C4Youth (Collaborative Centre on Care for Children and Youth), HBSC (Health Behaviour in School-aged Children). Zij stemden allen in met een interview. Deze interviews vonden medio 2013 plaats met dr. Öry, kinderarts maatschappelijke gezondheidszorg. De interviews waren voorgestructureerd rondom vragen over de karakteristieken van de studies, belangrijkste opbrengsten van het onderzoek in termen van beleid, onderzoek, en praktijk, en factoren die de studie positief en negatief beïnvloed hebben. De projectleider werd gevraagd te reflecteren op witte vlekken in relatie tot kennis en beleid op het terrein van kinderen en jeugdigen in Nederland waarop een longitudinale studie mogelijk een antwoord zou kunnen geven. De projectleiders ontvingen een conceptverslag van het interview ten behoeve van goedkeuring voor publicatie. Een definitieve uitwerking van de gesprekken is beschreven in het rapport van Klein Velderman en collega's [1]. In dit artikel worden in de resultaten karakteristieken van de studies en een aantal kernbevindingen samengevat, waarna in de discussie en conclusie stil wordt gestaan bij de betekenis van ervaringen in huidig onderzoek voor de toekomst van langlopende studies in Nederland.

\section{Resultaten}

\section{Karakteristieken van de studies}

De verschillende karakteristieken van de studies zoals het startjaar, het aantal deelnemers bij start, de leeftijd bij inclusie in de studie en het doel van de verschillende studies staan vermeld in tab. 1 .

\section{Opbrengsten van de studies}

Hieronder worden per studie de belangrijkste opbrengsten beschreven, zoals benoemd in de interviews. Voor overige opbrengsten verwijzen we naar de websites van de verschillende studies.

\section{Generation R}

Generation R [2] heeft veel wetenschappelijke output gegenereerd ( \pm 300 publicaties), en de eerste slagen naar de praktijk zijn gemaakt. Een belangrijke opbrengst van Generation $\mathrm{R}$ is het prospectief verkregen inzicht in het cruciale belang van vroege zwangerschap - het eerste trimester - voor de periode daarna. Dit was aanleiding voor het versterken van de preconceptiezorg in Rotterdam met oog voor leefstijl in de zwangerschap. Verder werd in Generation R inzicht verkregen in de blootstelling van zwangeren aan hoge niveaus luchtverontreiniging en de hogere kans op complicaties als gevolg daarvan. Het zicht van Generation R op etnische verschillen binnen Nederland is uniek. Op basis van de onderzoeksresultaten zijn bijvoorbeeld etnisch specifieke groeicurves voor in de baarmoeder gemaakt. Een ander voorbeeld betreft etnische verschillen in daadwerkelijk rookgedrag tijdens de zwangerschap. Zo bleken Turkse zwangere vrouwen in $40 \%$ van de gevallen te roken en Marokkaanse nauwelijks; belangrijke informatie voor verloskundigen.

\section{$\mathrm{ABCD}$}

In de ABCD studie [3] bleek in hoeverre taal een barrière is voor toegang tot gezondheid en zorg. Taalvaardigheid was bijvoorbeeld een belangrijke voorspeller voor gebruik van foliumzuur. Er kwam bovendien een aantal belangrijke etnische verschillen aan het licht. Zo bleek onder Surinaamse en Ghanese moeders vaker sprake van vroeggeboorte en een laag geboortegewicht. Overgewicht van kinderen was vaker een probleem in Marokkaanse en Turkse gezinnen. De ABCD studie biedt inzicht in hoe moeders tegen het gewicht van hun kind aankijken en hoe dit gerelateerd is aan het ontstaan van overgewicht. De studie leverde aanknopingspunten op voor interventies gericht op overgewicht. Bij Turkse gezinnen bleken meer risico's te bestaan ten aanzien van voeding en gewicht, daarom is voor deze doelgroep door de GGD een interventie ontwikkeld en geëvalueerd. De ABCD studie kent een unieke inbedding in de GGD standaardzorg en een goede samenwerking met zorgverleners.

\section{Universiteit Utrecht PIAMA}

Uit het PIAMA onderzoek [4] bleek dat er geen effect is van matrashoesjes op het ontstaan van astma en luchtwegallergie bij jonge kinderen. Buitenluchtverontreiniging is in PIAMA bestudeerd in groot Europees verband. De resultaten spelen een rol bij het opstellen van de WHO- en EPA-richtlijnen. Borstvoeding bleek belangrijk voor een gezond gewicht op de leeftijd van 7 jaar. Voe- 
Tabel 1 Karakteristieken van de verschillende studies.

\begin{tabular}{|c|c|c|c|c|c|c|c|}
\hline studie & website & regio & $\begin{array}{l}\text { type studie/ } \\
\text { cohort }\end{array}$ & startjaar & $\begin{array}{l}\text { aantal deelne- } \\
\text { mers bij start }\end{array}$ & $\begin{array}{l}\text { leeftijd } \\
\text { kinderen bij } \\
\text { start cohort }\end{array}$ & doel \\
\hline Generation R & $\begin{array}{l}\text { www.genera- } \\
\text { tionr.nl }\end{array}$ & Rotterdam & geboortecohort & 2002 & 10.000 & $\begin{array}{l}\text { vroege } \\
\text { zwanger- } \\
\text { schap }\end{array}$ & $\begin{array}{l}\text { Centraal staat de vraag waarom het ene } \\
\text { kind zich optimaal ontwikkelt en het andere } \\
\text { kind niet of minder }\end{array}$ \\
\hline$A B C D$ & $\begin{array}{l}\text { www.abcd- } \\
\text { studie.nl }\end{array}$ & Amsterdam & geboortecohort & 2003 & $\begin{array}{l}8000 \text { zwange- } \\
\text { ren en } 6700 \\
\text { kinderen }\end{array}$ & $\begin{array}{l}\text { zwanger- } \\
\text { schap }\end{array}$ & $\begin{array}{l}\text { Inventariseren en analyseren van factoren } \\
\text { in het vroege leven (tijdens de zwanger- } \\
\text { schap en op de jonge kinderleeftijd) die een } \\
\text { mogelijke verklaring vormen voor latere } \\
\text { gezondheid en gezondheidsverschillen }\end{array}$ \\
\hline $\begin{array}{l}\text { Universiteit } \\
\text { Utrecht } \\
\text { PIAMA }\end{array}$ & $\begin{array}{l}\text { www.piama. } \\
\text { iras.uu.nl }\end{array}$ & $\begin{array}{l}3 \text { regio's } \\
\text { (Noord } \\
\text { Nederland, } \\
\text { Midden Ne- } \\
\text { derland en } \\
\text { Rotterdam) }\end{array}$ & $\begin{array}{l}\text { interventie- } \\
\text { studie en } \\
\text { natuurlijke } \\
\text { beloopstudie }\end{array}$ & 1996 & 3963 & $\begin{array}{l}\text { zwanger- } \\
\text { schap (2 } \\
\text { maanden } \\
\text { voor ge- } \\
\text { boorte) }\end{array}$ & $\begin{array}{l}\text { Het eerste doel was de ontwikkeling van } \\
\text { astma en luchtwegallergie te bestuderen } \\
\text { (incl. effect van verschillende risicofactoren) } \\
\text { in de eerste acht levensjaren. Het tweede } \\
\text { doel was na te gaan of door het gebruik van } \\
\text { allergeendichte matras- en kussenhoezen } \\
\text { het ontstaan van astma en luchtwegallergie } \\
\text { bij jonge kinderen voorkomen kan worden }\end{array}$ \\
\hline TRAILS & www.trails.nl & $\begin{array}{l}\text { Noord } \\
\text { Nederland }\end{array}$ & $\begin{array}{l}\text { populatiecohort } \\
\text { en klinisch } \\
\text { cohort }\end{array}$ & $\begin{array}{l}2000 \\
2004 \\
\text { (klinisch } \\
\text { cohort) }\end{array}$ & $\begin{array}{l}2230 \\
543 \text { (klinisch } \\
\text { cohort) }\end{array}$ & $\begin{array}{l}\text { kinderen van } \\
10-12 \text { jaar }\end{array}$ & $\begin{array}{l}\text { Centraal staat de vraag hoe het gaat met } \\
\text { jongeren als ze opgroeien tot volwassenen } \\
\text { met als doel meer kennis te vergaren over } \\
\text { de oorzaken van (on)gezondheid }\end{array}$ \\
\hline KOALA & $\begin{array}{l}\text { www.koala- } \\
\text { study.nl }\end{array}$ & $\begin{array}{l}\text { heel Neder- } \\
\text { land }\end{array}$ & geboortecohort & 2001 & 2500 & $\begin{array}{l}\text { de } 14^{\text {de }} \\
\text { week van de } \\
\text { zwanger- } \\
\text { schap }\end{array}$ & $\begin{array}{l}\text { Doel van het onderzoek is om meer te weten } \\
\text { te komen over de oorzaken van allergie } \\
\text { en astma, en de ontwikkeling en groei van } \\
\text { kinderen }\end{array}$ \\
\hline $\begin{array}{l}\text { C4Youth } \\
\text { (TakeCare } \\
\text { onderzoek) }\end{array}$ & $\begin{array}{l}\text { www.c4y- } \\
\text { outh.nl }\end{array}$ & $\begin{array}{l}\text { provincie } \\
\text { Groningen }\end{array}$ & $\begin{array}{l}\text { populatiecohort } \\
\text { en zorgcohort }\end{array}$ & 2010 & 2000 & $\begin{array}{l}\text { kinderen en } \\
\text { jongeren van } \\
4-18 \text { jaar }\end{array}$ & $\begin{array}{l}\text { Antwoord krijgen op de vragen: "Wie krijgt } \\
\text { welke zorg en waarvoor?" en "Wat werkt er, } \\
\text { ook op de langere termijn?" }\end{array}$ \\
\hline HBSC & $\begin{array}{l}\text { www.hbsc- } \\
\text { nederland.nl }\end{array}$ & $\begin{array}{l}\text { heel Neder- } \\
\text { land }\end{array}$ & $\begin{array}{l}\text { vierjaarlijks } \\
\text { dwarsdoorsne- } \\
\text { de-onderzoek }\end{array}$ & 2001 & $\begin{array}{l}1500 \text { leerlingen } \\
\text { primair onder- } \\
\text { wijs (PO) en } \\
4500 \text { voortgezet } \\
\text { onderwijs (VO) }\end{array}$ & $\begin{array}{l}11-16 \text { jari- } \\
\text { gen (groep } \\
8 \text { P0 en klas } \\
1-4 \text { V0) }\end{array}$ & $\begin{array}{l}\text { Een landelijk beeld schetsen van het welbe- } \\
\text { vinden, de fysieke en geestelijke gezondheid } \\
\text { en de risicogedragingen van Nederlandse } \\
\text { schoolgaande kinderen van } 11-16 \text { jaar in de } \\
\text { context van het gezin, school, en de groep } \\
\text { leeftijdsgenoten }\end{array}$ \\
\hline
\end{tabular}

ding, ook van moeders tijdens de zwangerschap, bleek geassocieerd met het ontstaan van astmasymptomen. Het PIAMA onderzoek heeft ervoor gezorgd dat ook andere geboortecohortstudies nu intensiever naar de relatie tussen voeding en astma kijken.

\section{TRAILS}

TRAILS [5] bleek sterk in het nuanceren en vraagtekens zetten bij bepaalde genetische of psychofysiologische associaties: verbanden (bijvoorbeeld betreffende cortisol of het effect van bepaalde genen) bleken niet altijd zo sterk als verondersteld en niet voor iedereen te gelden. Ook een belangrijk deel van TRAILS betreft de psychische (on)gezondheid van jongeren in de periode tussen de kindertijd en volwassenheid. Het bleek dat jongeren die GGZ-zorg ontvangen niet altijd beter af dan jongeren zonder zorg.

\section{KOALA}

Uniek in de KOALA cohortstudie [6] is het grootschalige onderzoek naar de rol van darmflora bij de immunologische ontwikkeling (met poepmonsters van ruim duizend kinderen). Het onderzoek wees uit dat kinderen die thuis geboren zijn minder risico hebben op eczeem en astma dan in het ziekenhuis geboren kinderen. Dit verschil werd verklaard door de darmflora (aanwezigheid darmbacterie Clostridium difficile). Er wordt vanuit KOALA samengewerkt met het PIAMA onderzoek.

\section{C4Youth}

In het populatiecohort binnen het TakeCare onderzoek van C4Youth [7] is sprake van een gemiddelde mate van sociale en emotionele problemen. De groep die licht pedagogische hulpverlening krijgt, heeft een verhoogd probleemniveau. Bij de jongeren die zorg ontvangen in de Jeugdzorg of GGZ is sprake van stevig verhoogde problematiek. C4Youth is erin geïnteresseerd te volgen hoe dit zich in de verschillende groepen op langere termijn ontwikkelt en hoopt de meting na de decentralisatie van de zorg voor jeugd nog eens te herhalen.

\section{HBSC}

De HBSC studie betreft een herhaalde transversale studie (bijvoorbeeld Harakeh et al.) [8]. Iedere 4 jaar wordt een 
random dwarsdoorsnede gemaakt van een groep 11-16 jarigen; in 2014 betreft dit de vierde keer. HBSC Nederland is onderdeel van internationaal onderzoek in ruim 40 landen. Met de resultaten van HBSC Nederland kan dus een vergelijking gemaakt worden met een groot aantal landen om a) na te gaan in welk opzicht Nederlandse kinderen verschillen van kinderen in andere landen op een groot aantal indicatoren voor welbevinden, gezondheid en risicogedragingen, en; b) verklaringen te zoeken voor de verschillen die zijn gevonden tussen kinderen uit verschillende landen. Alleen door deze internationale vergelijking is bijvoorbeeld bekend dat Nederlandse jeugdigen hoog scoren op welbevinden, en dat zij extreem veel drinken. De studie toont verder aan dat vele zaken uit het HBSC onderzoek stabiel zijn door de jaren heen, zoals roken. Dan blijkt het dus niet nodig ten behoeve van beleid ieder jaar opnieuw onderzoek te doen naar roken.

\section{Positieve en belemmerende factoren}

De projectleiders werd gevraagd naar factoren die een positieve bijdrage hadden in de totstandkoming van de studieresultaten. Zij noemden een aantal factoren die te maken hebben met draagvlak en steun van relevante betrokkenen. Dit betrof betrokkenheid en medewerking van zowel kennis- als praktijkinstellingen, draagvlak bij belanghebbenden (bijvoorbeeld zorgverleners) en het bestuurlijk veld, samenwerking binnen Nederland en Europees verband, en zowel inhoudelijke als financiele steun. Ten behoeve van succesvolle dataverzameling werden genoemd: goede registraties in Nederland, een hoge deelnamebereidheid en hoog vertrouwen in de onderzoekspopulatie, persoonlijk contact met de deelnemers en creativiteit bij de dataverzameling (bijvoorbeeld leuk maken voor respondenten door te meten in de dierentuin, of met een bakfiets langs scholen om het meten makkelijk te maken). Tot slot zijn volgens de projectleiders continuïteit in het onderzoeksteam, een duidelijke herkenbare focus van de studie en een goede website voor deelnemers positieve factoren in het onderzoek gebleken.

$\mathrm{Er}$ is ook een aantal factoren genoemd die juist het succes van de studies in de weg zitten. Om te beginnen kan de samenwerking met het bestuurlijk veld soms beter en heeft men te maken met bestuurlijke dynamiek (wisseling op sleutelposities). Een belangrijk knelpunt betreft de financiën: er is vaak weinig geld of onzekerheid daarover, de timing van het geld is heel belangrijk, anders worden kansen gemist (subsidierondes en planning van dataverzameling lopen regelmatig uit de pas). Daarnaast is de looptijd van financiering soms te kort voor een hele ronde van dataverzameling, de infrastructuur verkoopt niet en ook PR kost geld. Bovendien zijn particuliere investeerders moeilijk te vinden en er zijn onvoldoende middelen om alle verzamelde data te analyseren (nota bene: er zijn ook zogenoemde datakerkhoven, verzamelde data die verweesd zijn en waar niemand meer interesse in heeft). Daarbij gaven de projectleiders aan steeds de noodzaak te voelen, te innoveren en meer te doen dan een volgende ronde van dataverzameling. Dit terwijl mankracht in de studies gemiddeld al beperkt is. Andere belemmerende factoren die de projectleiders noemden zijn de inspanning die het kost om de steekproef te behouden (uitdaging van de follow-up), de uitdaging van dataverzameling met multi-informanten, het missen van dingen (diepte) door de breedte van de studie, mogelijk wantrouwen bij deelnemers over privacy en het soms 'onbetrouwbare imago van wetenschap'.

\section{Discussie en conclusie}

De Nederlandse grootschalige studies naar kinderen en jeugdigen hebben de afgelopen decennia een waardevolle bijdrage kunnen leveren aan de zorg voor jeugd. In de resultaten van deze zeven Nederlandse grootschalige longitudinale en herhaalde transversale studies lazen we bijvoorbeeld over verbeterde preconceptiezorg, internationale richtlijnen ten aanzien van buitenluchtverontreiniging, oog voor de relatie tussen voeding en astma, en kennis over stabiliteit van roken onder jeugdigen. Toch zou een relatieve buitenstaander zich af kunnen vragen waarom er in Nederland zoveel van dergelijke grootschalige studies zijn op het terrein van kinderen en jeugdigen. Dit is ook alleen zinvol als studies elkaar aanvullen en versterken, als kennis en ervaring gebundeld worden en er voor onderzoekers onderling en andere geïnteresseerden zicht is op wat er al is of wordt onderzocht, of er al data is die de vraag beantwoordt, en wat de lessons learned zijn van lopend onderzoek. Op dit moment is dat in Nederland niet goed geregeld. Daarom pleiten we voor een verzamelplaats met een gestandaardiseerde beschrijving van de inhoud van deze studies. Dit om te bevorderen dat onderzoekers en andere geïnteresseerden kunnen vinden welke constructen gemeten zijn en volgens welke methodiek, zodanig dat zij de bruikbaarheid ervan kunnen beoordelen voor hun vragen. Naast informatie over constructen en methoden, kan geregistreerd worden welke mogelijkheden de studie biedt voor onderzoek door wetenschappers buiten de onderzoeksgroep. Initiatieven in die richting zijn genomen door bijvoorbeeld ZonMw in samenwerking met RIVM-Zorggegevens en CentERdata. Zie verder ook de rapportage 'Van gegevens verzekerd' van de Raad voor Gezondheidsonderzoek [9] en zie www.birthcohorts.net en www.chicosproject.eu voor Europese initiatieven om overzicht te schetsen van cohortstudies. Op basis van de bevindingen in ons evaluatieonderzoek ondersteunen wij plannen in deze richting.

De projectleiders benoemden bestaande datakerkhoven. Er worden meer data verzameld dan er met de beschikbare middelen geanalyseerd kunnen worden. Ook zijn er soms wisselingen in het onderzoeksteam, verliest men interesse in de data, en is niet alle data hoofdzaak in het onderzoek. Een voordeel van zorgvuldig overzicht van beschikbare data en informatie over toegankelijkheid daarvan, is dat mogelijk anderen nuttige conclusies kun- 
nen verbinden aan informatie die nu in eventuele datakerkhoven ligt. Bovendien kan alleen door helder zicht op lopend onderzoek inzichtelijk worden wat onderlinge verschillen en de toegevoegde waarde van de verschillende onderzoeken is. Men kan zodoende niet alleen komen tot verdere verrijking van de opbrengsten uit deze studies, maar bovendien goed in kaart brengen waar nog lacunes zijn. In de interviews werd een aantal onderwerpen genoemd in relatie tot kennis en beleid op het terrein van kinderen en jeugdigen in Nederland waarop langlopende studies in de toekomst een antwoord zouden kunnen geven [1]. Zo werden gedragsproblemen en opvoedingsstijlen door enkele projectleiders als mogelijke onderwerpen genoemd. Bij opvoedingsstijlen is het te adviseren om de focus niet alleen op het kind of de jeugdige te leggen, maar op het gehele gezin. Ook zou in longitudinaal onderzoek de uitwerking van de transitie naar gemeenten op jeugd en gezinnen gemonitord kunnen worden (zoals de projectleider van C4Youth benoemde).

Bovengenoemde betreft toekomstig onderzoek. In alle interviews bleek echter al hoe moeilijk het is om continuïteit van het huidige onderzoek te waarborgen, terwijl de waarde van dit type onderzoek staat of valt met continuïteit. Op basis van de interviews stellen wij dat dit probleem voor een groot deel gelegen is in financiering, die werd door de projectleiders bestempeld als een 'lappendeken' en is vaak niet structureel. Aanbevolen wordt om op bestuurlijk niveau te praten over het belang en de continuïteit van dit type onderzoek, in combinatie met een discussie over eigenaarschap.

\section{Literatuur}

1. Klein Velderman M, Pannebakker FD, Öry F. Langlopend grootschalig onderzoek naar kinderen en jeugdigen in Nederland: Wat heeft het gebracht en waar leidt het ons naartoe? Leiden: TNO Behavioural and Societal Sciences; 2013.
2. Jaddoe VWV, Bakker R, Duijn CM Van, Heijden AJ Van der, Lindemans J, Mackenbach JP, et al. The Generation R Study Biobank: a resource for epidemiological studies in children and their parents. Eur J Epidemiol. 2007;22:917-23. doi:10.1007/s10654-007-9209-z.

3. Eijsden M Van, Vrijkotte TGM, Gemke RJBJ, Wal MF Van der. Cohort profile: the Amsterdam Born Children and their Development (ABCD) study. Eur J Epidemiol. 2011:40:1176-86. doi:10.1093/ije/dyq128.

4. Brunekreef B, Smit J, Jongste J De, Neijens H, Gerritsen J, Postma D, et al. The prevention and incidence of asthma and mite allergy (PIAMA) birth cohort study: design and first results. Pediatr Allergy Immunol. 2002:13:55-60. doi:10.1034/j.1399-3038.13.s.15.1.x.

5. Huisman M, Oldehinkel AJ, Winter A de, Minderaa RB Bildt A de, Huizink AC, et al. Cohort profile: the Dutch 'TRacking Adolescents' Individual Lives' Survey'; TRAILS. Int J Epidemiol. 2008:37:1227-35. doi:10.1093/ije/dym273.

6. Kummeling I, Thijs C, Penders J, Snijders BEP, Stelma F, Reimerink J, et al. Etiology of atopy in infancy: the KOALA birth cohort study. Pediatr Allergy Immunol. 2005:16:67984. doi:10.1111/j.1399-3038.2005.00333.x.

7. Knorth E, Eijk L van, Noordik E, Tuinstra J, Reijneveld M. De sociaal-emotionele ontwikkeling van drieduizend kinderen in en buiten de zorg op de voet gevolgd. Kind \& Adolescent Praktijk. 2011;10:192-4. doi:10.1007/ s12454-011-0049-3.

8. Harakeh Z, Looze ME De, Schrijvers CTM, Dorsselaer SAFM Van, Vollebergh WAM. Individual and environmental predictors of health risk behaviours among Dutch adolescents: the HBSC study. Public Health. 2012:126:566-73. doi:10.1016/j.puhe.2012.04.006.

9. Grobbee DE, Bakker DH, Coebergh JWW, Deeg DJH, Maas PJ van der, Postma DS, et al. Van gegevens verzekerd: Kennis over de volksgezondheid in Nederland nu en in de toekomst. Den Haag: RGO; 2008.

M. Klein Velderman, onderzoeker TNO

F.D. Pannebakker, onderzoeker TNO 